\title{
FENOLOGIA E CRESCIMENTO DO PINHÃO-MANSO CULTIVADO NA ZONA DA MATA DO ESTADO DE ALAGOAS, BRASIL
}

\section{PHENOLOGY AND GROWTH OF THE PHYSIC NUT IN THE FLOREST ZONE OF THE STATE OF ALAGOAS, BRAZIL}

\author{
Claudiana Moura dos SANTOS ${ }^{1,2}$ \\ Laurício ENDRES ${ }^{3}$ \\ Humberto Cristiano de Lins WANDERLEY FILHO ${ }^{4}$ \\ Eduardo Vicente ROLIM ${ }^{4}$ \\ Vilma Marques FERREIRA ${ }^{5}$
}

\begin{abstract}
RESUMO
O pinhão-manso (Jatropha curcas L.) pertence à família Euforbiaceae, é uma planta nativa das Américas, encontrase disseminada pela América Tropical, Ásia e África, com interesse para cultivo devido ao uso da semente como matériaprima na obtenção de óleo para produção de biodiesel. Esse trabalho teve como objetivo caracterizar o comportamento fenológico do pinhão-manso cultivado na Zona da Mata de Alagoas. Foram efetuadas avaliações de crescimento e da fenologia de setembro/2006 a dezembro/2007 em indivíduos localizados no campo experimental do Centro de Ciências Agrárias da Universidade Federal de Alagoas, no Município de Rio Largo. Foram realizadas avaliações quinzenais de crescimento em 50 indivíduos e semanais de abscisão e brotamento das folhas, floração e frutificação em 20 indivíduos. Também foram acompanhados 20 indivíduos para contagem do número de inflorescências, botões florais, flores e frutos por planta e 10 indivíduos para acompanhamento do desenvolvimento do fruto. O pinhão-manso apresentou crescimento vegetativo lento na estação seca, e aceleração do crescimento na estação chuvosa. A abscisão foliar iniciou durante o final do período chuvoso e continuou durante a época seca, onde alguns indivíduos entraram em dormência vegetativa. Verificouse pico de floração e frutificação durante a estação chuvosa. Este estudo sugere que os eventos vegetativos e reprodutivos do pinhão-manso são sazonais, concentrando o seu desenvolvimento de forma mais intensa na estação chuvosa.
\end{abstract}

Palavras-chave: planta oleaginosa; frutificação; Jatropha curcas; biodiesel.

\section{ABSTRACT}

The physic nut (Jatropha curcas L.), pertains to the Euphorbiaceae family, is a native plant of Americas and naturalised throughout tropical America, Asia and Africa. Part of the interest for the cultivation of this species is related to the use of the seeds for oil production for the obtainment of the bio-diesel. This work had as objective to characterize the phenologic behavior of the physic nut for the city of Rio Largo, Alagoas. Some growth and phenologic observations were taken during the period of September 2006 to December 2007 in plants located in an experimental field, in the Center of Agrarian Sciences of the Federal University of Alagoas, in the city of Rio Largo. Some records on growth were taken biweekly on 50 plants, and weekly on leaf fall and sproutings, budding and fruiting on 20 plants. Twenty plants were also observed for counting (the number of inflorescence per plant, the number of flower buttons per plant, the number of flowers per plant and the number of fruits per plant) and 10 plants to observe the development of the fruit. The Physic nut presented vegetative growth with pattern seasonal; slow growth was verified during the dry season, and accelerated growth during the rainy season. The leaf fall initiated during the end of the rainy season and continued through the dry season, where some plants entered into dormancy. A budding and fruiting peak was verified during the rainy season. This study suggests that the vegetative and reproductive events of the physic nut showed themselves as seasonal, concentrating on a more intense way its phenological activities during the rainy season.

Key-words: oil plant; fruiting; Jatropha curcas; bio-diesel.

\footnotetext{
${ }^{1}$ Parte da Dissertação de mestrado da primeira autora.

2 Aluno de Pós-Graduação em agronomia - Produção Vegetal, Universidade Federal de Alagoas -Campus Delza Gitaí, Br 104 Norte, km 85 , Rio Largo, Alagos, Brasil. E- mail: claudianabio@hotmail.com.

${ }^{3}$ Eng. Agr. Dr. Prof. Adjunto. Departamento de Fitotecnia. Centro de ciências agrária, Laboratório de Fisiologia Vegetal, Universidade Federal de Alagoas, Av. Lourival Melo Mota, s/n,Tabuleiro do Martins, Maceió, Alagoas, Brasil. CEP: 57072-970. E-mail: endres@pq.cnpq.br. Autor para correspondência.

${ }^{4}$ Laboratório de Fisiologia Vegetal, Universidade Federal de Alagoas -Campus Delza Gitaí, Br 104 Norte, km 85 , Rio Largo, Alagoas, Brasil. Email: cristianowanderley@hotmail.com; edu_bio@ibest.com.br

${ }^{5}$ Eng. Agr. Dr. Prof. Adjunto. Departamento de Fitotecnia. Centro de ciências agrária, Laboratório de Fisiologia Vegetal, Universidade Federal de Alagoas -Campus Delza Gitaí, Br 104 Norte, km 85 , Rio Largo, Alagoas, Brasil. E-mail: vilmaferreira@ceca.ufal.br
} 
SANTOS, C.M. et al. Fenologia e crescimento do pinhão-manso...

\section{INTRODUÇÃO}

O pinhão-manso (Jatropha curcas L.), pertencente à família Euphorbiaceae, é uma planta nativa das Américas, apresenta-se disseminada nas regiões tropicais e subtropicais do globo e amplamente distribuído na Ásia, África e Índia (Divakara et al., 2010). No Brasil, o pinhão-manso se adapta a condições edafoclimáticas variáveis, com sua distribuição geográfica indo desde o estado de São Paulo até Norte e Oeste do país, ocorrendo, sobretudo nos estados do Nordeste, em Goiás e Minas Gerais (Drummond et al., 1984), sendo considerado uma interessante opção agrícola para a região Nordeste, por ser uma espécie nativa e com alta resistência ao estresse hídrico (Arruda et al., 2004; Maes et al., 2009).

O pinhão-manso é uma planta perene, um arbusto grande, de crescimento rápido alcançando uma altura de três a cinco metros, mas pode atingir um altura de 8 metros em condições favoráveis (Divakara et al., 2010), as folhas são decíduas, a primeira inflorescência é cimeira; a planta apresenta abscisão foliar na estação seca, as quais ressurgem logo após as primeiras chuvas (Saturnino et al., 2005). Os frutos maduros apresentam o epicarpo com coloração externa marrom-escura e os frutos secos apresentam o epicarpo de coloração preta (Nunes et al., 2008).

Parte do interesse pelo cultivo desta espécie está relacionada ao uso do grão como matéria-prima, sendo empregada na produção de óleo para a obtenção do biodiesel, e na fabricação de sabão e tinta, além disso, a planta também pode ser usada como cerca viva, e empregada em indústrias farmacêuticas e cosméticas (Augustus et al., 2002; Kheira \& Atta, 2009).

No Brasil, sob condições de sequeiro, a planta do pinhão-manso cresce em regiões com precipitações pluviométricas variando de 480 a $2.380 \mathrm{~mm}$ anuais e temperaturas médias anuais entre $18{ }^{\circ} \mathrm{C}$ e $28,5^{\circ} \mathrm{C}$ (Saturnino et al., 2005). No entanto, ela cresce melhor com chuvas anuais acima de $600 \mathrm{~mm}$, sendo tolerante a longos períodos de estiagem (Severino et al., 2006).

Estudos sobre o padrão fenológico de comunidades ou populações vegetais fornecem informações sobre ritmos de crescimento e reprodução, interações com o clima, produção de frutos e sementes (Fisch et al., 2000). Além disso, a avaliação do comportamento fenológico propicia o conhecimento e a definição das épocas em que ocorrem as diversas fases do período vegetativo das plantas, o que pode favorecer a melhor utilização das práticas culturais, conhecimento da dinâmica fenológica e servir como base para a elaboração de estratégias de cultivos (Bergamaschi, 2007).

Nos trópicos, fatores climáticos e interações interespecíficas estão freqüentemente associados com a sazonalidade dos eventos fenológicos das plantas (Bencke \& Morellato, 2002). Trabalhos recentes indicam que a sazonalidade está presente em maior ou menor grau na ocorrência dos eventos fenológicos em espécies tropicais (Fagundes et al., 2007; Folgarait et al., 2007).

Em adição, estudos mostram as influências dos fatores climáticos nos eventos fenológicos em diversas espécies de Jatropha. Maya \& Arriaga (1996) estudando as espécies J. cinerea (Ortega) Müll. Arge. e J. cuneata Wiggins \& Rollins. constataram que 0 desenvolvimento está diretamente correlacionado ao período chuvoso. Já Sayer \& Newbery (2003) verificaram a influência da pluviosidade nas diversas fenofases em J. gaumeri Greenm. e observaram um alto índice de abscisão foliar com o fim da época chuvosa. Santos et al. (2005) estudando as espécies de J. mutabilis (Pohl) Baill. e J. mollissima (Pohl) Baill. típicas de áreas de Caatinga, observaram que as espécies possuíam padrão de floração do tipo contínuo produzindo flores ao longo de todo o ano, apresentando pico de floração entre os meses de outubro e novembro. A abscisão foliar, formação de folhas novas, floração e frutificação são as quatro principais fenofases consideradas na maioria desses estudos.

Pouco se sabe sobre efeitos do ambiente no crescimento, no desenvolvimento e na produtividade do pinhão-manso. Dessa forma, trabalhos que visem determinar padrões fenológicos, além de fornecerem informações de interesse produtivo, são relevantes subsídios para a compreensão da dinâmica da cultura e para planos de manejo. Além disso, o conhecimento da fenologia dessa cultura é de grande interesse uma vez que se dispõe de uma série de informações sobre crescimento e desenvolvimento, as quais podem ser utilizadas para programas de melhoramento quantitativo e qualitativo da espécie. Assim, esse trabalho teve como objetivo caracterizar o comportamento fenológico da espécie pinhão-manso cultivado na Zona da Mata do estado de Alagoas.

\section{MATERIAL E MÉTODOS}

O estudo fonológico do pinhão-manso (Jatropha curcas L.) foi realizado em indivíduos cultivado no campo experimental, do Centro de Ciências Agrárias da Universidade Federal de Alagoas, no Município de Rio Largo, estado de Alagoas, situado em torno das coordenadas geográficas $09^{\circ} 27^{\prime} 57,3^{\prime \prime} \mathrm{S}$ e $35^{\circ} 49^{\prime} 57,4^{\prime \prime} \mathrm{W}$, em uma altitude média de $127 \mathrm{~m}$ acima do nível do mar, no período de período de janeiro/2006 a dezembro/2007.

A área de estudo está situada na Zona da Mata alagoana que possui um clima quente e semiúmido com um período chuvoso entre abril e agosto (70\% da precipitação total anual acontecem neste período) e um período seco de setembro a fevereiro, caracterizada por temperatura do ar média anual de $25,5{ }^{\circ} \mathrm{C}$; umidade relativa do ar de $70 \%$ e precipitação pluviométrica média de 1816,4 $\mathrm{mm}$ ano $^{-1}$ (Souza et al., 2005).

Os dados climáticos do período
obtidos na


SANTOS, C.M. et al. Fenologia e crescimento do pinhão-manso...

meteorológica automática do Centro de Ciências Agrárias da Universidade Federal de Alagoas UFAL ( $\left.9^{\circ} 27^{\prime} \mathrm{S}, 35^{\circ} 27^{\prime} \mathrm{W}, 127 \mathrm{~m}\right)$, a 100 metros do experimento. Foi calculada a média mensal dos valores diários para temperaturas máxima, média e mínima, umidade relativa do ar e a soma da pluviosidade acumulada de cada mês (Figura 1).
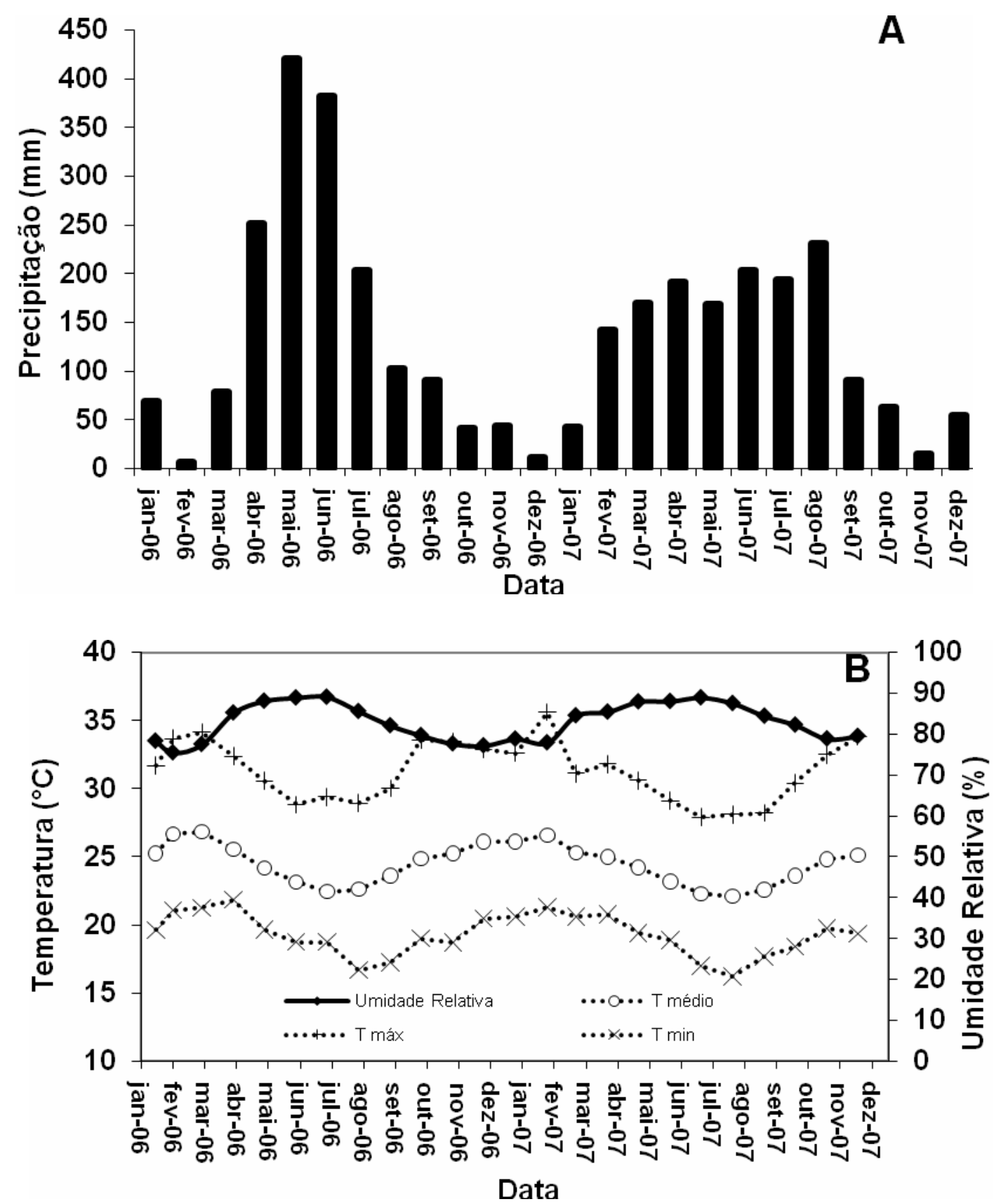

FIGURA 1 - Pluviosidade média durante o período experimental (A) e temperatura média (-o-), máxima (-+-), mínima (-X-), e Umidade relativa (- -), do período de janeiro/2006 a dezembro/2007 (B) para a região de Rio Largo-AL.

Para a realização do estudo, foram utilizadas sementes de pinhão-manso obtidas de várias plantas matrizes provenientes do município de Eusébio, Ceará. As sementes foram germinadas em casa de vegetação e com aproximadamente três meses de idade, as mudas foram transplantas para o campo, utilizando espaçamento $3,0 \times 2,0 \mathrm{~m}$, numa área de $2.588 \mathrm{~m}^{2}$, totalizando 444 plantas. Durante o transplante todas as plantas receberam adubação de base constituída por $200 \mathrm{~g}$ por planta da fórmula 12-12-12 $\left(\mathrm{N}-\mathrm{P}_{2} \mathrm{O}_{5}-\mathrm{K}_{2} \mathrm{O}\right)$. Os tratos culturais e o combate às formigas foram feitos 
SANTOS, C.M. et al. Fenologia e crescimento do pinhão-manso...

sempre que necessário. Quando as plantas atingiram seis meses de idade, iniciou-se o acompanhamento dos parâmetros de crescimento e fenologia.

Para avaliar o crescimento das plantas, foram marcados 50 indivíduos e mensurados quinzenalmente a altura (distância da superfície do solo até o meristema mais alto) e o diâmetro do caule (base do caule) das plantas no período entre setembro/2006 e dezembro/2007.

As observações fenológicas foram realizadas semanalmente em 20 indivíduos nesse mesmo período, onde foram acompanhadas e avaliadas a presença de botões, flores, frutos, folhas novas e abscisão foliar, seguindo indicações de Bencke \& Morellato (2002). O critério de avaliação para presença de botões, flores e frutos, foi estimado quando $50 \%$ dos indivíduos apresentaram respectivas fenofases.

Para obtenção de mais detalhes sobre o tempo de duração para cada fenofase foram anotados a partir da observação dos indivíduos marcados, o número de inflorescências, número de botões florais, número de flores abertas e número de frutos por planta entre o período de abril/2007 a dezembro/2007.

Para acompanhar o crescimento do fruto, foram selecionadas 10 plantas de aproximadamente $140 \mathrm{~cm}$ de altura, nas quais foram marcadas uma inflorescência por planta. Observou-se o período de desenvolvimento das inflorescências até o surgimento dos botões florais. Nesse período, foram marcados um ramo por inflorescência por planta com aproximadamente 70 botões por inflorescência, com cerca $2 \mathrm{~mm}$ de diâmetro cada botão floral, os quais foram avaliadas até a senescência. A partir desta fase, 20 frutos, sendo dois por planta, medindo aproximadamente $2,5 \mathrm{~mm}$ foram selecionados e o diâmetro do fruto medido com paquímetro semanalmente até a completa senescência do fruto.

Foi utilizada a correlação de Pearson ( $r$ ) para verificar a relação entre as variáveis fenológicos e os dados climáticos do período de estudo.

\section{RESULTADOS E DISCUSSÃO}

Durante o período de estudo foi possível observar duas estações climáticas bem definidas: uma seca entre os meses de setembro a fevereiro e outra chuvosa entre os meses abril a agosto, sendo agosto o mês mais chuvoso $(230,63 \mathrm{~mm})$ e dezembro o mais seco $(10,92 \mathrm{~mm})$. Esses períodos foram também, respectivamente, os de maior e menor umidade relativa (Figura $1 \mathrm{~A}$ ). A temperatura média durante o período experimental foi de $24,5^{\circ}$ C, com umidade relativa do ar de $82,85 \%$, e a precipitação total foi $3248,9 \mathrm{~mm}$. Não foi observada grande variação de temperatura durante o experimento, sendo fevereiro o mês mais quente com temperatura média de $26,6^{\circ} \mathrm{C}$ e agosto o mês mais frio com temperatura média de $22,10{ }^{\circ} \mathrm{C}$ (Figura 1B).

O pinhão-manso apresentou média de 30 $\mathrm{cm}$ de altura e $23 \mathrm{~mm}$ de diâmetro do caule aos seis meses de idade, atingindo, com 21 meses de idade, altura média de $147 \mathrm{~cm}$ e diâmetro do caule de 80 mm (Figura 2). Ginwal et al. (2004); Rao et al. (2008) e Gohil \& Pandya (2009) também observaram resultados semelhantes para altura e diâmetro do caule em diferentes genótipos de pinhão-manso. Segundo os mesmos autores, esses parâmetros de crescimento podem ser usados na estimação de herdabilidade genética da planta contribuindo na seleção de populações melhoradas.

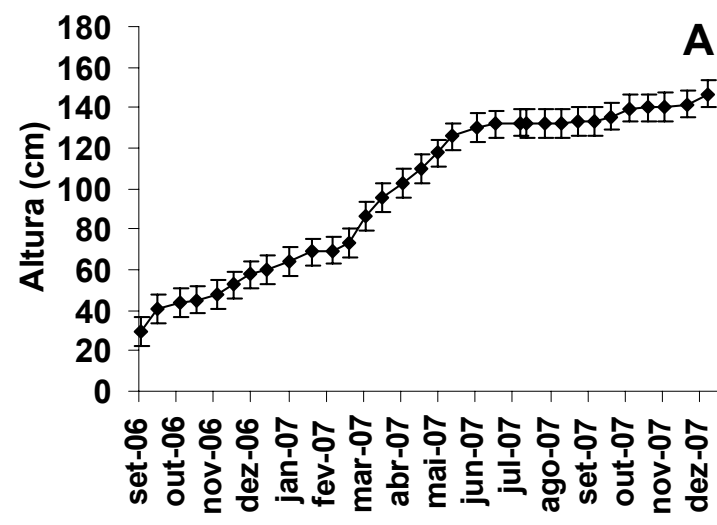

Data
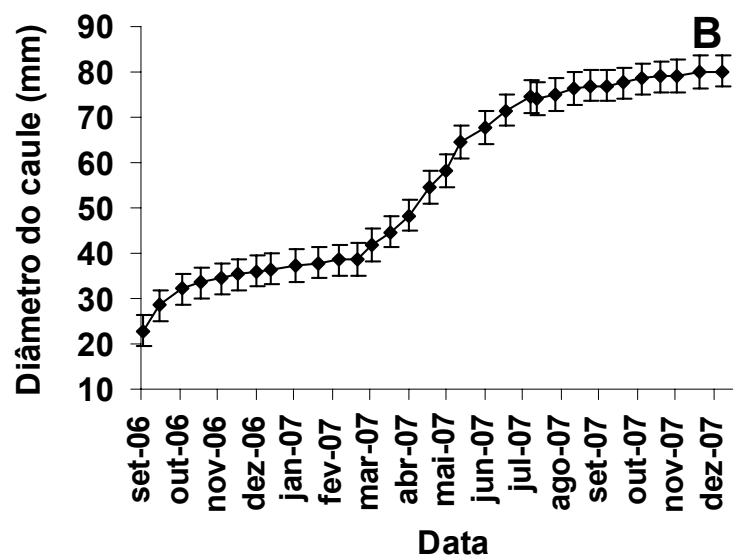

FIGURA 2 - Altura (cm) e (B) diâmetro do caule $(\mathrm{mm})$ de Jatropha curcas dos seis aos 21 meses de idade, no município de Rio Largo-AL, situado entre as coordenadas geográficas $09^{\circ} 27^{\prime} 57,3^{\prime \prime} S$ e $35^{\circ} 49^{\prime} 57,4$ "W 
SANTOS, C.M. et al. Fenologia e crescimento do pinhão-manso...

A espécie apresentou entre os meses de setembro/2006 a março/2007 uma taxa de crescimento médio de $7,3 \mathrm{~cm}$ mês $^{-1}$ e $3,15 \mathrm{~cm}$ mês $^{-1}$ para diâmetro do caule. Entre setembro e dezembro de 2007 essa taxa foi menor, com média de $5 \mathrm{~cm}$ mês $^{-1}$ e $1,3 \mathrm{~cm}$ mês ${ }^{-1}$ para altura e diâmetro do caule, respectivamente (Figura 2). Esses períodos de crescimento lento coincidiram com a época seca nos dois anos. A aceleração no crescimento vegetativo ocorreu durante a estação chuvosa, entre abril a agosto de 2007, apresentando uma taxa de crescimento médio de $12,3 \mathrm{~cm} \mathrm{mês}{ }^{-1}$ (Figura 2). Em regiões de clima quente e seco foi observado em plantas de pinhãomanso crescimento mais lentos de $10 \mathrm{~cm}$ no primeiro ano e 20 a $40 \mathrm{~cm}$ no segundo ano (Meng et al., 2009), o que provavelmente seja uma resposta a planta ao período seco da região. De acordo a Saturnino et al. (2005), conforme a região, o desenvolvimento inicial das mudas de pinhão-manso pode ser influenciado pela época de chuvas, ventos dominantes e outras ocorrências climáticas típicas de cada local.

Foi verificada uma forte correlação positiva entre o diâmetro do caule e a altura da planta $(r=0,98$ e $p<0,01)$ (Tabela 1). Este padrão coincide com o evidenciado por Ginwal et al. (2004) que verificaram correlação de $r=0,91$ para as mesmas variáveis. Já Rao et al. (2008) constataram correlação positiva entre altura e produtividade de $r=0,36$, efeito que influenciou no aumento do rendimento dos grãos. A altura da planta também apresentou uma correlação positiva com a umidade relativa $(r=0,54, p<0,05)$ e negativa com a temperatura média $(r=-0,53, p<0,05)$ (Tabela 1). O diâmetro do coleto correlacionou negativamente com a temperatura média $(r=-0,60$, $p<0,05)$. Ambos os parâmetro fenológicos não apresentaram correlação com a precipitação.

TABELA 1 - Coeficientes de correlação de Pearson entre as fenofases e fatores climáticos para umidade relativa, temperatura média (T.med), temperatura máxima (T.max) e temperatura mínima (T.min), observadas em plantas jovens de pinhão-manso sobre condições de campo, período de setembro/2006 a dezembro/2007, município de Rio Largo-AL.

\begin{tabular}{cccccccc}
\hline Variável & $\begin{array}{c}\text { Altura da } \\
\text { planta }\end{array}$ & $\begin{array}{c}\mathrm{N}^{\circ} \text { flores } \\
\text { abertas }\end{array}$ & $\begin{array}{c}\text { Precipitação } \\
\text { pluviomemtrica }\end{array}$ & $\begin{array}{c}\text { Umidade } \\
\text { relativa }\end{array}$ & T.méd & T.máx & T.mín \\
\hline $\begin{array}{c}\text { Altura da } \\
\text { planta }\end{array}$ & - & - & 0,36 & $0,54^{*}$ & $-0,53^{*}$ & $-0,48$ & $-0,25$ \\
$\begin{array}{c}\text { Diâmetro do } \\
\text { caule }\end{array}$ & $0,98^{* *}$ & - & 0,25 & 0,47 & $-0,60^{*}$ & $-0,50$ & 0,25 \\
$\begin{array}{c}\mathrm{N}^{\circ} \text { botões } \\
\text { florais }\end{array}$ & - & $0,93^{* *}$ & $-0,11$ & $-0,25$ & $0,85^{* *}$ & $0,71^{*}$ & $0,95^{* *}$ \\
$\begin{array}{c}\mathrm{N}^{\circ} \text { flores } \\
\text { abertas }\end{array}$ & - & - & 0,10 & 0,02 & 0,52 & 0,50 & $0,83^{* *}$ \\
\hline
\end{tabular}

O surgimento de novas folhas foi freqüente durante todo ano, sendo mais intensidade no período chuvoso, de maio a junho, quando ocorreu aceleração no brotamento de gemas e maior taxa de crescimento de folhas (Figura 1 e 3) e com menos intensidade, durante os meses de outubro/2006 a abril/2007 e setembro/2007 a dezembro/2007 correspondentes a estação seca (Figura 3). O mesmo comportamento foi observado em outras espécies de Jatropha, como em J. cinerea e J. cuneata (Maya \& Arriaga, 1996) e J. gaumeri (Sayer \& Newbery, 2003), em que se observou o surgimento de novos brotos com o aumento da pluviosidade.

A abscisão foliar iniciou com o fim da fase reprodutiva nos meses de julho e agosto de 2007 (Figura 3), com período de alta pluviosidade e temperaturas mais baixas (Figura 1), aumentando de intensidade com a diminuição da precipitação, chegando aos meses de setembro/2006 e 2007, no início da estação seca, com cerca de $70 \%$ de desfolhamento (dados não mostrados), sugerindo a influência de outros fatores ambientais, além da disponibilidade de água, sobre a fenologia da espécie, conforme discutido anteriormente.

Durante o experimento, a maioria das plantas permaneceu com um mínimo de folhas no início da estação seca, e uma minoria entrou em dormência vegetativa durante esse período. Henning (2009) diz que a dormência do pinhãomanso é induzida pelas mudanças climáticas em especial temperatura/luminosidade, mas nem todas as plantas respondem a esse estímulo, podendo-se ter num cultivo, tanto ramos desfolhados, como outros cheios de folhas verdes.

A taxa de abscisão foliar continuou elevada em dezembro/2006, o que deve ter sido ocasionado pelas interferências dos fatores climáticos a exemplo da baixa pluviosidade acumulada no mês (10,1 mm). Tal observação não foi constatada no mês de dezembro/2007, o qual apresentou surgimento de folhas novas, e ausência de abscisão foliar, talvez devido ao maior índice de chuva acumulada $(54,35 \mathrm{~mm})$ (Figura 1 e $3)$. 


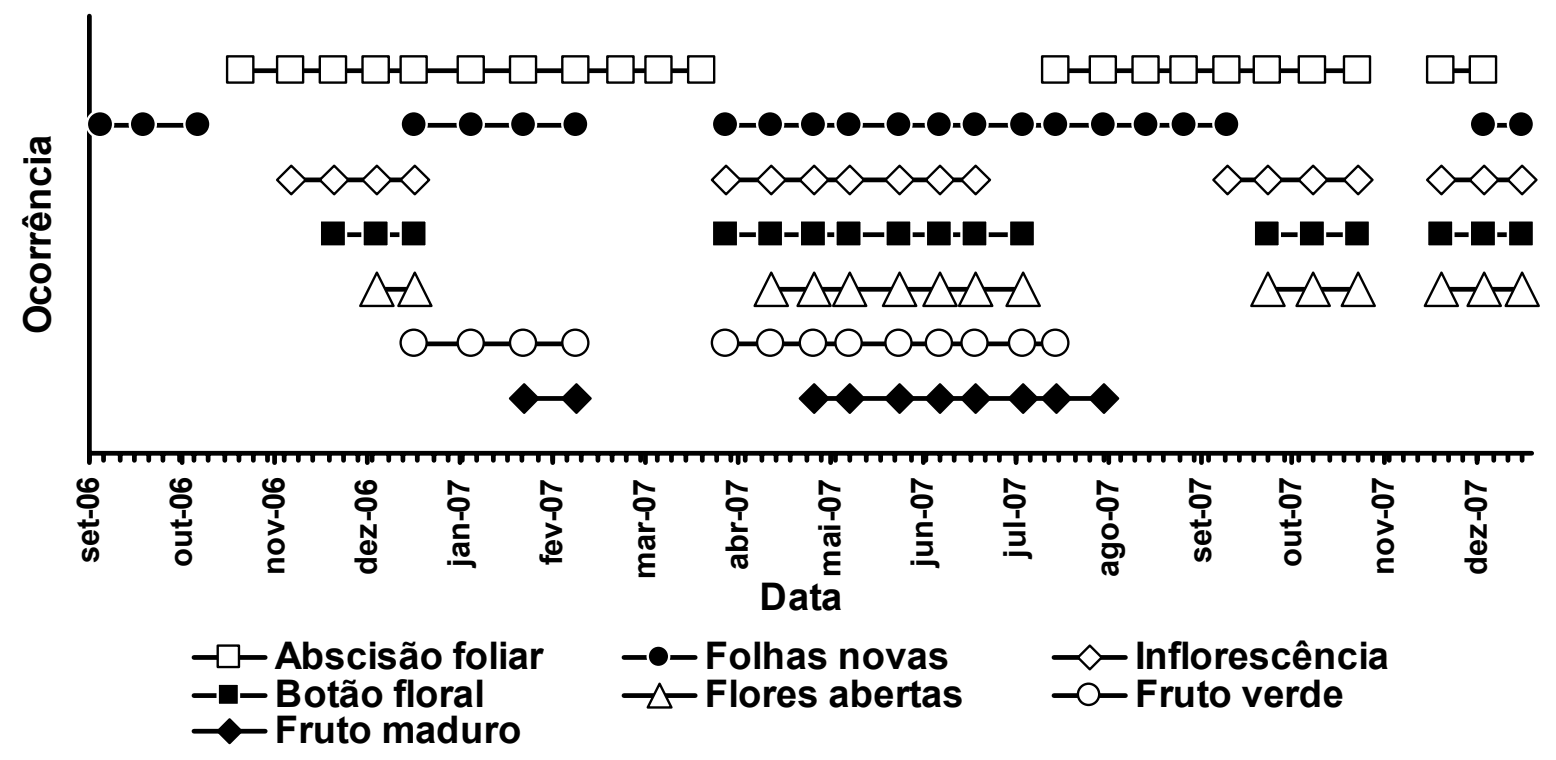

FIGURA 3 - Fenograma de Jatropha curcas L. estudada no município de Rio Largo-AL, situado entre as coordenadas geográficas $09^{\circ} 27^{\prime} 57,3^{\prime \prime} \mathrm{S}$ e $35^{\circ} 49^{\prime} 57,4$ "W.

De acordo a Sartunino et al. (2005) o pinhão-manso apresenta comportamento decíduo, onde as folhas caem em parte ou totalmente no final da época seca ou durante a estação chuvosa. Segundo o mesmo autor, o pinhão-manso permanece em repouso, até o começo da primavera, ou da época das chuvas nas regiões secas. Assim, as espécies podem ser classificadas como decíduas quando apresenta abscisão e produção de folhas concentradas em determinada época, ficando por um período de tempo quase ou totalmente sem folhas (Santos \& Takaki, 2005). Arruda et al. (2004) relatam que o pinhão-manso é uma planta de baixa exigência hídrica tolerando bem o período de seca, calor ou frio, e sob condições extrema de seca, a planta perde as folhas para conservar a umidade em seus tecidos, o que resulta em paralisação do crescimento e passando a sobreviver à custa da água e das reservas orgânicas armazenada em seu caule.

O intervalo de 15 meses (setembro/2006 a dezembro/2007) escolhido para este estudo (duas estações secas e uma chuvosa) permitiu observar que todas as plantas apresentaram inflorescências e fase reprodutiva durante o período de estudo. A primeira fase de florescimento correu ao longo do período da estação seca entre novembro-dezembro/2006, em indivíduos com apenas seis meses de idade, o que também foi verificado no ano seguinte entre novembro-dezembro/2007 (Figura 3), em que ambos apresentaram baixo índice de floração (Figura 4) fato que se explica por nesses períodos apresentaram elevadas temperaturas e baixo índice pluviométrico (Figura 1). Já a segunda floração ocorreu durante o início das chuvas em abril-julho/2007.

O principal período de floração teve início em abril; apresentando um pico em junho/2007 (Figura 3 e 4A), durante o período chuvoso. Observou-se que a maioria das inflorescências surgiu no período chuvoso (cerca de sete inflorescências por planta) em relação ao período seco (cerca de três inflorescências por planta) (Figura 4A). Cada inflorescência teve a duração média de 50 dias entre o seu surgimento e a formação dos primeiros frutos.

Comportamento semelhante de florescimento foi encontrado em diferentes regiões de clima tropical e subtropical. Raju \& Ezradanam (2002) verificaram floração do pinhão-manso durante a estação chuvosa, muitas vezes com dois picos de floração, ou seja, durante verão e outono na Índia. Meng et al. (2009) estudando pinhãomanso em regiões de clima quente na China verificaram que a planta florescem duas vezes ao ano apresentando duas frutificações, entretanto em algumas regiões seca a floração só ocorreu uma vez por ano devido a baixa disponibilidade hídrica do solo. Em regiões permanentemente úmidas a floração foi observada durante todo o ano (Heller, 1996). Esses resultados mostram a influência do clima na fase reprodutiva da planta.

O pico de floração (botões florais e flores abertas) ocorreu entre abril e junho, coincidindo com a estação chuvosa (Figura 4B e 4C). Todas as plantas de pinhão-manso floresceram durante $O$ período chuvoso, tal comportamento homogêneo se deve aos indivíduos apresentarem as mesmas idades seguindo assim o mesmo ciclo cronológico. Segundo Rathcke \& Lacey (1985) padrões fenológicas em indivíduos da mesma espécie com diferentes idades e regiões, cultivados em ambiente natural, podem refletir resultados heterogêneos ao longo da variação sazonal, como a diferenciação na floração; diferentes espécies 
SANTOS, C.M. et al. Fenologia e crescimento do pinhão-manso...

cultivadas no campo de forma homogênea também apresentaram os mesmos padrões fenológicos são particularmente definidas a exemplo da sorva
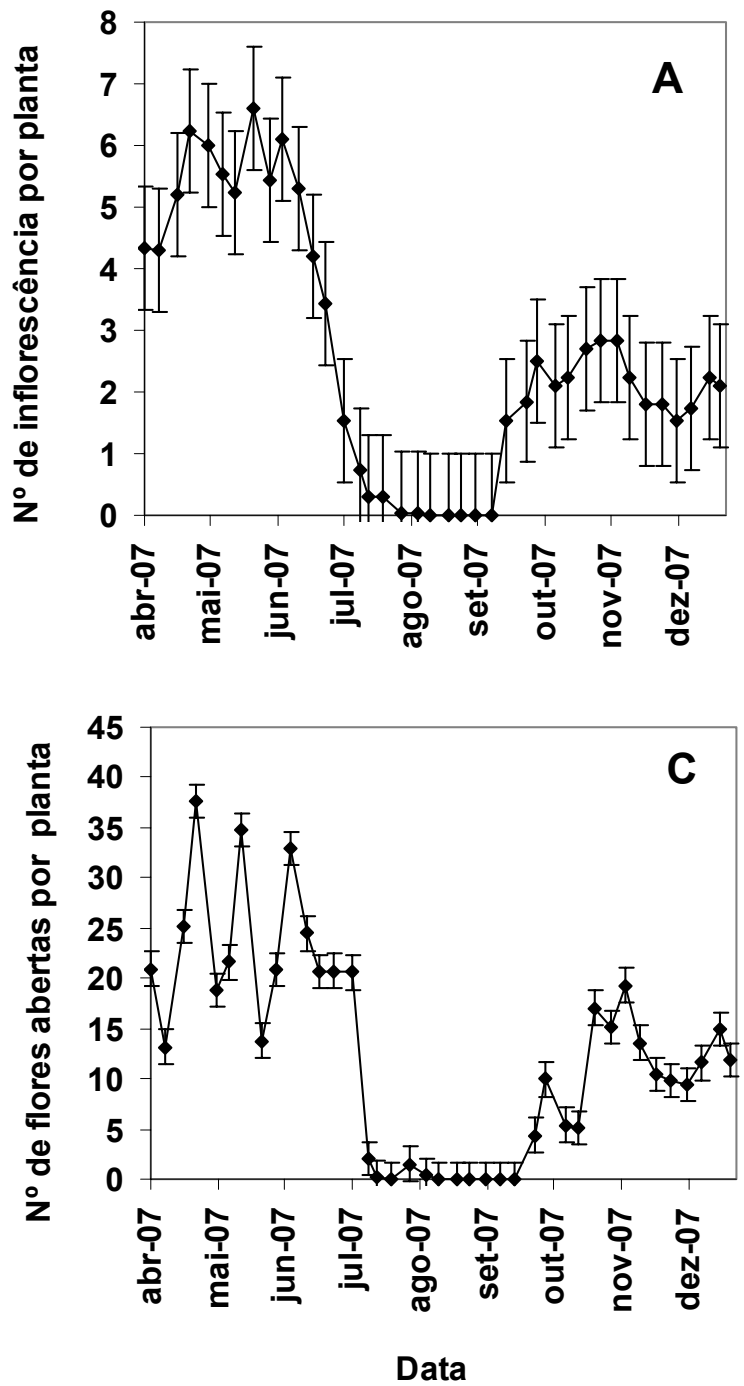

(Falcão et al., 2003) e da nogueira (Sacramento \& Pereira, 2003).
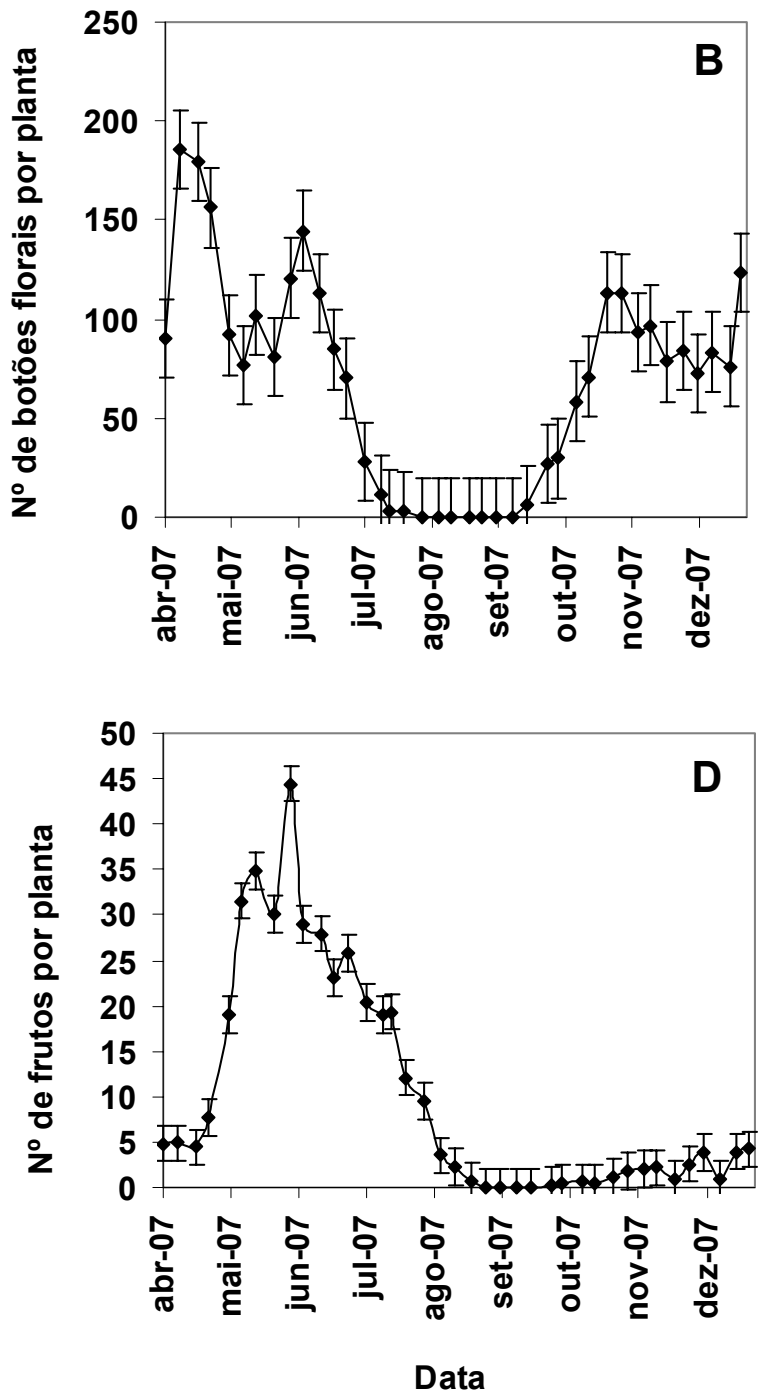

FIGURA 4 - Número de inflorescências (A), número de botões florais (B), número de flores abertas (C) e número de frutos (D) por indivíduos de Jatropha curcas $\mathrm{L}$. produzidos no município de Rio Largo-AL, durante o período de abril a dezembro de 2007.

O número de botões florais apresentaram correlação positiva com a temperatura média, máxima e mínima, já o número de flores aberta apenas apresentou correção com a temperatura mínima $(r=0,83, p<0,05)$, durante a floração (Tabela 1). O que evidencia que a variação da temperatura tem uma forte influencia sobre o início de floração. Dhillon et al. (2006) constataram que com a queda na temperatura ocorreu o aumento de flores masculinas e diminuição de flores femininas em pinhão-manso, o que sugere que temperaturas baixas interferem nas fenofases da cultura.

A análise de correlação demonstrou que a fenofase número de flores abertas apresentou correlações positivas $(r=0,93, p<0,01)$ com os números de botões florais (Tabela 1). Outras correlações positivas foram verificados por Rao et al. (2008) entre números de flores e ramos $(r=0,4)$ e números de flores com taxa de flores femininas $e$ masculinas $(r=0,4)$ em pinhão-manso.

As plantas de pinhão-manso apresentaram os primeiros frutos em meados de dezembro/2006, coincidindo com a estação seca (Figura 1 e 3) em plantas com apenas nove meses de idade, no entanto com produtividade bastante baixa (dados não mostrados). Nesse período foi registrada a presença de frutos verdes em dezembro e o surgimento de frutos maduros entre janeiro e fevereiro de 2007 (Figura 3).

A segunda frutificação iniciou-se entre os meses de abril e maio/2007 e estendeu-se até agosto de 2007 apresentando maior intensidade 
SANTOS, C.M. et al. Fenologia e crescimento do pinhão-manso...

nos meses de junho e julho em que $100 \%$ das plantas estavam com frutos, com frutos maduros sendo observados a partir de julho até início de agosto (Figura 3). A quantidade de frutos alcançou uma média de 45 frutos por planta no mês de junho/2007 com plantas de 15 meses de idade (Figura 4D).

De acordo com Arruda et al. (2004) o início da produção do pinhão-manso é por volta do décimo mês após o plantio, mas a produção só atinge a plenitude por volta do terceiro ou quarto ano, podendo chegar aos 40 anos de idade produzindo. No Brasil, sob as condições climáticas de Minas Gerais, a florada do pinhão-manso iniciouse após o período da seca e os frutos puderam ser colhidos de fevereiro a abril, caso o terreno receba irrigação ou chuvas regulares o pinhão-manso pode produzir o ano todo, com colheitas mensais dos frutos (Drummond et al., 1984).

Verificou-se que durante o período de formação do botão floral até a abertura destes (antese) levou em média 55 dias. O ciclo de desenvolvimento, compreendendo o crescimento, maturação e amadurecimento pleno e início aos sinais de senescência, foi em média de 65 dias a partir da antese (Figura 5). A fase de rápido crescimento do fruto iniciou entorno dos 10 dias após antese e seguiu até 35 dias em que o fruto apresentou diâmetro médio em torno de $30 \mathrm{~mm}$, iniciando a fase estacionária, caracterizada por um crescimento lento, com um período de estabilização dos 35 até 45 dias, quando ocorreu o amadurecimento dos primeiros frutos (Figura 5). Esses dados corroboram com Rao et al. (2008) que verificaram o número médio de dias de frutificação a maturidade dos frutos foram entre 35 e 48,7 dias. Segundo Moura et al. (2003) o desenvolvimento dos frutos geralmente é dividido em três estágios maiores: crescimento, maturação, e senescência. O período de crescimento geralmente envolve divisão celular, alongamento celular, enchimento onde acontece o aumento físico do fruto e maturação.

\section{Data}

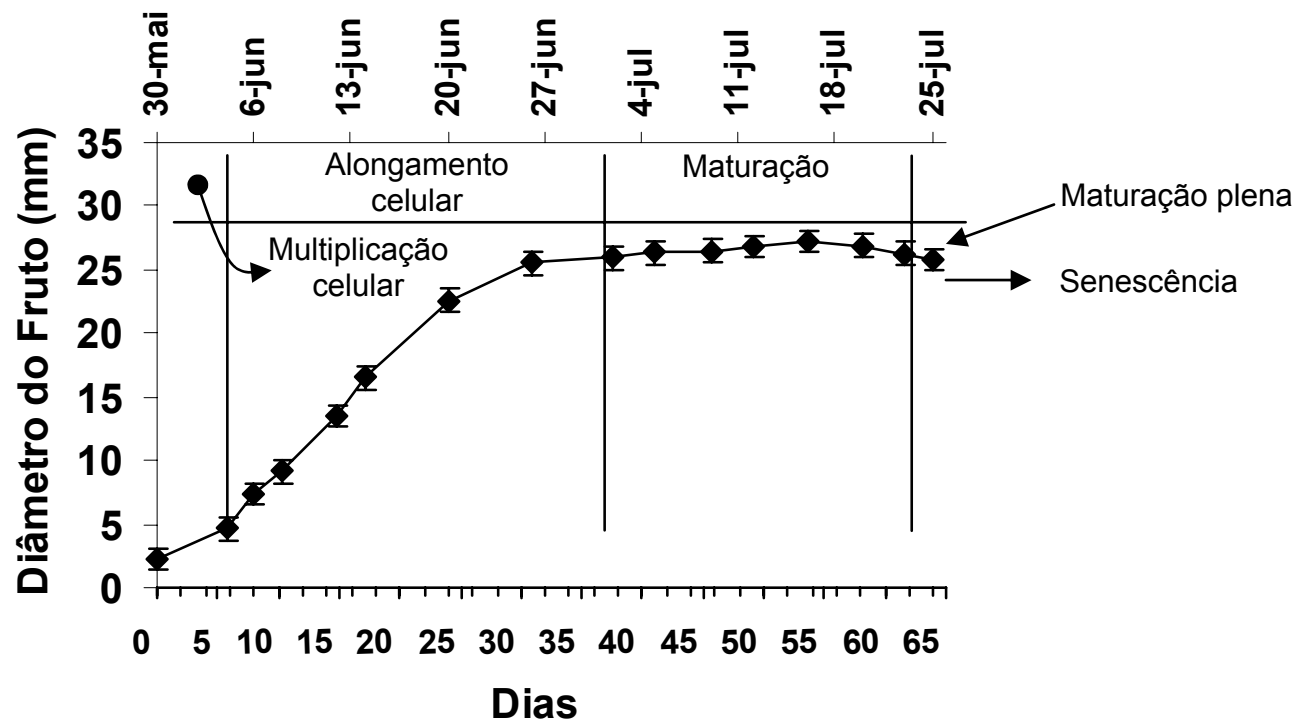

FIGURA 5 - Seqüências de médias semanais do diâmetro $(\mathrm{mm})$ dos frutos de pinhão-manso (período após a antese) até seu amadurecimento.

O ciclo completo de reprodução do pinhãomanso desde o surgimento da inflorescência até o amadurecimento pleno do fruto na planta teve duração média de 120 dias. A maturação dos frutos foi considerada completa quando as cápsulas apresentaram coloração marrom e preta. $O$ fruto se apresentou deiscente e o peso seco médio foi de $3 g$. Resultados semelhantes foram encentrados por Arruda et al. (2004) que relatam o fruto de pinhãomanso como sendo capsular ovóide com diâmetro de 1,5 a $3,0 \mathrm{~cm}$, por Sartunino et al. (2005) que observaram frutos com diâmetro 2 a $2,5 \mathrm{~cm}$ e peso média $2,9 \mathrm{~g}$ e por Nunes et al. (2008) que descrevem os frutos de pinhão-manso maduros com epicarpo de coloração marrom-escura, enquanto os frutos secos apresentam coloração preta.

\section{CONCLUSÕES}

O cultivo em campo de Jatropha curcas $L$. na Zona da Mata de Alagoas apresenta uma dinâmica fenológica sazonal, com crescimento vegetativo lento durante a estação seca.

A floração e frutificação ocorrem com maior intensidade nos meses chuvosos. Já o surgimento de folhas novas ocorre ao longo de todo o ano com maior intensidade durante períodos chuvosos. O ciclo completo de formação, desenvolvimento e maturação do fruto se estende por 120 dias. 
SANTOS, C.M. et al. Fenologia e crescimento do pinhão-manso...

\section{REFERÊNCIAS}

1. ARRUDA, F. P. et al. Cultivo de pinhão-manso (Jatropha curcas L.) como alternativo para o semi-árido nordestino. Revista brasileira de Oleaginosas e Fibrosas, v. 8, n. 1, p. 789-799, 2004.

2. AUGUSTUS, G. D. P. S.; JAYABALA, N. M.; SEILERB, G. J. Evaluation and bioinduction of energy components of Jatropha curcas. Biomass and Bioenergy, v. 23, n. 3, p. 161-164, 2002.

3. BENCKE, C. S. C.; MORELLATO, P. L. C. Comparação de dois métodos de avaliação da fenologia de plantas, sua interpretação e representação. Revista Brasileira de Botânica, v. 25, n. 3, p. 269-275, 2002.

4. BERGAMASCHI, H. O clima como fator determinante da fenologia das plantas. In: REGO, G. M.; NEGRELLE, R. R. B.; MORELLATO, L. C. (Org.). Fenologia ferramenta para conservação, melhoramento e manejo de recursos vegetais arbóreos. 1. ed. Colombo: Embrapa Florestas, 2007. p. 291-310.

5. DHILLON, R. S. et al. Clonal propagation and reproductive biology in Jatropha curcas L. Indian Journal Agroforest; $v$. 8, n. 2, p. 18-27, 2006.

6. DIVAKARA, B. N. et al. Biology and genetic improvement of Jatropha curcas L.: a review. Applied Energy, v. 87, n. 3, p. $732-742,2010$.

7. DRUMMOND, O. A. et al. "Cultura do pinhão manso". Belo horizonte: EPAMIG, 1984. 99 p.

8. FAGUNDES, M.; ARAÚJO, L. S. A.; NUNES, Y. R. F. Efeitos do estágio sucessional do habitat na fenologia do pequizeiro (Caryocar brasiliense: Caryocaraceae). Revista Brasileira de Biociências, v. 5, n. 1, p. 144-146, 2007

9. FALCÃO, M. A; CLEMENT, R. C.; GOMES, J. B. M. Fenologia e produtividade da sorva (Couma Utilis (MART.) na Amazônia Central. Acta Botanica Brasílica, v. 17, n. 4, p. 541-547, 2003.

10. FISCH, S. T. V.; NOGUEIRA JR, L. R.; MANTOVANI, W. Fenologia reprodutiva de euterpe edulis mart. na mata atlântica (reserva ecológica do Trabiju, Pindamonhangaba - SP). Revista de Biociências de Taubaté, v. 6, n. 2, p. 3137, 2000.

11. FOLGARAIT, P. J.; PATROCK, R. J. W.; GILBERT, L. E. The influence of ambient conditions and space on the phenological patterns of a Solenopsis phorid guild in an arid environment. Biological Control, v. 42, n. 3, p. 262-273, 2007.

12. GINWAL, H. S.; RAWAT, P. S.; SRIVASTAVA, R. L. Seed source variation in growth performance and oil yield of Jatropha curcas Linn. in Central India. Silvae Genetica, v. 53, n. 4, p. 186-192, 2004.

13. GOHIL, R. H.; PANDYA, J. B. Genetic evaluation of jatropha (Jatropha curcas Linn.) genotypes. Journal of Agricultural Research, v. 47, n. 3, p. 221-228, 2009.

14. HELLER, J. Physic nut (Jatropha curcas L.): promiting the conservation and use of underutilized and neglected crops. Roma: IPGRI, 1996. 66 p.

15. HENNING, R. K. The Jatropha System. An integrated approach of rural development. 2009. Disponvel em: <http :// www.jatropha.de/documents/The\%20 Jatropha\%20Book-2009.pdf>. Acesso em: 17 abril 2010.

16. KHEIRA, A. A. A.; ATTA, N. M. M. Response of Jatropha curcas L. to water deficits: Yield, water use efficiency and oilseed characteristics. Biomass and Bioenergy, v. 33, n. 10, p. 1343-1350, 2009.

17. MAES, W. H. et al. Plant-water relationships and growth strategies of Jatropha curcas $L$. seedlings under different levels of drought stress. Journal of Arid Environments, v. 73, n. 10, p. 877-884, 2009.

18. MAYA, Y.; ARRIAGA, L. Litterfall and phenological patterns of the dominant overstorey species of a desert scrub community in north-western Mexico. Journal of Arid Environments, v. 34, n. 1, p. 23-35, 1996.

19. MENG, Y. et al. Current situation and prospects of Jatropha curcas as a multipurpose tree in China. Agroforestry Systems, v. 76, n. 2, p. 487-497, 2009.

20. MOURA, F. T. et al. Evolução do crescimento e da maturação de frutos de cajazeira (Spondias mombin L.). Proceedings of the Interamerican Society for Tropical. Fruit/Frutales, v. 47, n. 1, p. 231-233, 2003.

21. NUNES, C. F. et al. Diferentes suplementos no cultivo in vitro de embriões de pinhão-manso. Pesquisa Agropecuária Brasileira, v. 43, n. 1, p. 9-14, 2008.

22. RAJU, A. J.; EZRADANAM, V. Pollination ecology and fruiting behaviour in a monoecious species, Jatropha curcas $L$. (Euphorbiaceae). Current Issue, v. 83, n. 11. p. 1395-1398, 2002.

23. RAO, G. R. et al. Genetic associations, variability and diversity in seed characters, growth, reproductive phenology and yield in Jatropha curcas (L.) accessions. Trees, v. 22, n. 5, p. 697-709, 2008.

24. RATHCKE, B.; LACEY, E. P. Phenological patterns of terrestrial plants. Annual Review of Ecology and Systematics, v. 16, n. 1 , p. $179-214,1985$

25. SACRAMENTO, C. K.; PEREIRA, F. M. Fenologia da floração da nogueira macadâmia (Macadamia integrifolia Maiden \& Betche) nas condições climáticas de Jaboticabal, São Paulo, Brasil. Revista Brasileira de Fruticultura, v. 25, n. 1, p. 19-22, 2003.

26. SANTOS, M. J.; MACHADO, I. C.; LOPES, A. V. Biologia reprodutiva de duas espécies de Jatropha (Euphorbiaceae) em Caatinga, Nordeste do Brasil. Revista Brasileira de Botânica, v. 28, n. 2, p. 361-373, 2005.

27. SANTOS, D. L.; TAKAKI, M. Fenologia de Cedrela fissilis Vell. (Meliaceae) na região rural de Itirapina, SP, Brasil. Acta Botanica Brasílica, v. 19, n. 3, p. 625-632, 2005.

28. SARTUNINO, M. H. et al. Produção de oleaginosas para biodiesel. Informe Agropecuário, v. 26, n. 229, p. 44-78, 2005

29. SAYER, E. J.; NEWBERY, D. M. The role of tree size in the leafing phenology of a seasonally dry tropical forest in Belize, Central American. Journal of Tropical Ecology, v. 19, n. 5, p. 539-548, 2003.

30. SEVERINO, L. S. et al. Viagem á Índia para Prospecção de Tecnologias sobre Mamona e Pinhão-Manso. Campina Grande: Embrapa Algodão, 2006. 56 p. (Documentos, 153)

31. SOUZA, J. L.; NICÁCIO, R. M.; MOURA, M. A. L. Global solar radiation measurements in Maceió Brazil. Renewable Energy, v. 30, n. 8, p. 1203-1220, 2005.

Recebido em 11/08/2009 Aceito em 16/03/2010 
